\title{
Standalone hybrid power system using homer software optimal case sizing of ferraguig (North West of Algeria)
}

\author{
B. Afif ${ }^{1}$, B. Merabet $^{2}$, A. Benhamou ${ }^{3}$, A. Chaker $^{4}$ \\ ${ }^{1,2}$ Faculty of Sciences and Technology, University of Mustapha Stambouli, Algeria \\ ${ }^{3}$ Energetic Department, University of Boumerdes, Algeria \\ ${ }^{4}$ Department of electrical engineering, SCAMRE Laboratory, Algeria
}

\begin{tabular}{l} 
Article Info \\
\hline Article history: \\
Received Jan 29, 2019 \\
Revised Mar 21, 2019 \\
Accepted Apr 20, 2019 \\
\hline
\end{tabular}

\section{Keywords:}

Hybrid system

Solar energy

Photovoltaic's

Homer software

\begin{abstract}
Rural areas suffer from high costs of grid extensions obliging institutions to provide for other remedies for consumers, like using generators (GE) diesel often considered as economic and reliable solutions, but at the detriment of some order environment pollution and users convenience. Furthermore, the continuous decline in GEs prices based on a renewable energy (RE) and the increasing reliability of these systems have lead to a greater use of renewable energy sources for power generation in remote areas. A property which limits the use of renewable energy is related to the variability of resources. Fluctuations in load according to annual or daily periods are not necessarily correlated to the resources. In remote areas, the preferred option is the coupling between multiple sources, such as wind turbines and solar panels, this coupling is called hybrid power system. Algeria's geographic location presents several advantages for the development and use of renewable energy, namely, solar energy and wind energy. In addition, Algeria has huge deposits of natural gas, $98 \%$ electricity comes from gas. Therefore, currently, the production of electricity from renewable energies primarily depends on their competitiveness with economic gas. Studied technological feasibility and economic viability of the hybrid system (PV/fuel) electrification project in a school located in Ferraguig succeed to reduce high costs, energy dependence, fuel supply problem, complicated/expensive maintenance, low lifetime, impossibility of 24 hours electricity production and waste oil management issues, by using renewable energy. HOMER model is used here to size a proposed system and determine an optimum configuration.
\end{abstract}

Copyright () 2019 Institute of Advanced Engineering and Science. All rights reserved.

Corresponding Author:

B. Merabet,

Faculty of Sciences and Technology,

University of Mustapha Stambouli,

Avenue Cheikh El Khaldi, Mascara 29000, Algeria.

Email: b.merabet@univ-mascara.dz

\section{INTRODUCTION}

Solar photovoltaic (PV) technology, in terms of energy for a healthy planet and safer world, is the most promising candidate for the coming decades, and a renewable technologies, which has a potential to shape clean, reliable, scalable and affordable electricity systems for the future [1]. Conventional energy resources are threaten to be exhausted, and it's necessary to develop alternative renewable clean energy technologies, away from the growing concern of greenhouse gas emissions and other environmental problems [2-3]. But, electricity in the developing countries is almost supplied by conventional thermal or hydroelectric power stations. Algeria, whose power is mainly based on conventional resources, situated between $36^{\circ} 42^{\prime} \mathrm{N}$ (latitude) and $03^{\circ} 13^{\prime} \mathrm{E}$ (longitude), contains many dwellings localized in isolated areas or significantly far from electricity grids, where connecting these to power grids is expensive and sometimes 
impossible. That's why autonomous systems are interesting for meeting the energy needs of the inhabitants of such regions. Using diesel generators is often considered as an economical and reliable solution, but generating some environmental nuisances for users. This country is an ideal place for using the solar energy. PV systems provide uninterrupted electricity without noise or environmental nuisance, are easy to install, require little maintenance and are highly reliable. However, the high investment cost required for their installation and the limitation of the electrical load to be satisfied (due to the intermittent nature of solar sources) are their crippling problems. Moreover, PV system performances depend strongly on the geographical location and type of PV modules used, and such systems are useful in areas having good amount of incident solar radiation. Thus, a hybrid system can be a solution to the problems encountered in diesel or PV systems alone by adding the advantages and eliminating the disadvantages.

On another hand, developing a hybrid power system for any application such as homes, educational institutes, industries; an engineer needs a basic knowledge on technology, availability of resources, economics, sizing, regulations. Renewable energy is an energy that comes from resources naturally replenished on a human timescale, such as sunlight, wind, rain, tides, waves, and geothermal heat. It replaces conventional fuels in four distinct areas: electricity generation, air and water heating/cooling, motor fuels, and rural (off-grid) energy services. To generate electric power with good efficiency, always co-generation or hybrid systems are always useful. A hybrid energy system usually consists of two or more renewable energy sources used together with conventional resources to provide more efficiency to the system and greater balance in energy supply to load. [4] The intermittent nature of Solar and wind leads to power outages due to insufficient solar energy and lack of wind speed. [5] Hence, diesel generator is also considered for its continuous electrical power generation. [6] To ensure the reliable operation of the system a storage device can be incorporated to meet the load demands. Researchers proved that the hybrid PV/Wind/battery system is a reliable electricity source for which public support is globally increasing day by day [7-8]. The energy generated by people can be utilized their homes and the excess can be sent to grid, which will be an additional income. [9] We aim in this paper to answer the following question: To feed a given isolated site in Algeria, are hybrid systems technically, economically and environmentally profitable compared to the conventional diesel solution alone and the extension of the electricity grid? If so, what are the performances of these systems?

\section{LET'S FIRST IDENTIFY OUR SITE}

Douar Sidi Abbou, a small village on which we had focused, belongs to Mascara city (North west of Algeria, exactly Mohammadia sub-prefecture and Ferraguig area. It is $380 \mathrm{~km}$ far from Algiers, and over 60 $\mathrm{km}$ from the coast. The north of Algeria has a Mediterranean climate and forms $4 \%$ of the country area [10]. Despite its small size, this part of the country is inhabited by more than ninety percent of Algeria's population, due it is land fertility and existence of rivers. [11] The average annual rainfall in Ferraguig is 487 $\mathrm{mm}$. [12] In Figure 1, we give a satellite image of the area, where PV panels are optimally orientated towards the south should have an optimum angle of $45^{\circ}$.

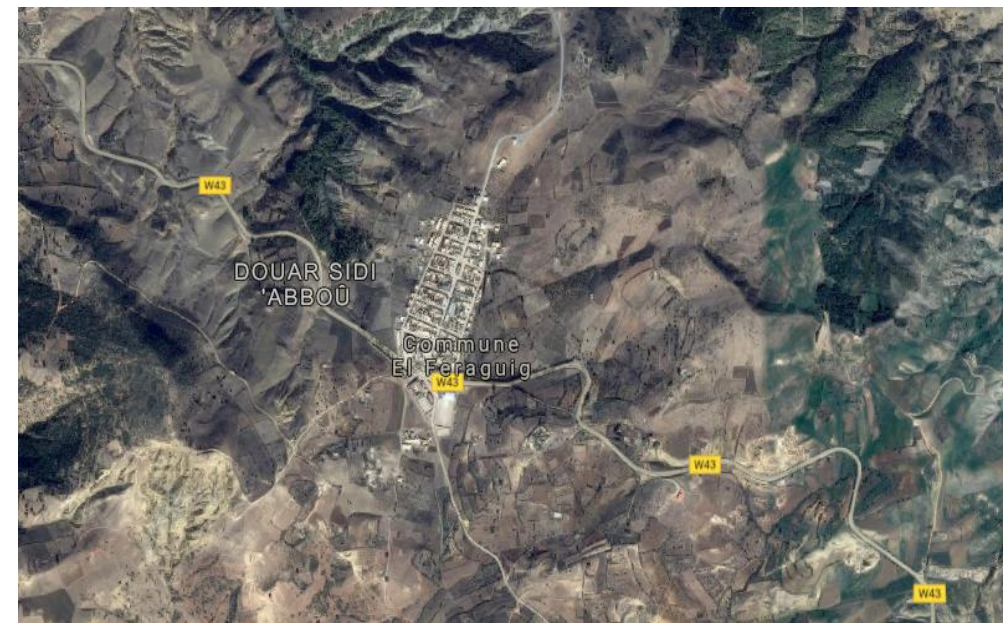

Figure 1. Satellite image of Ferraguig area [13] 


\section{SIMULATION BY HOMER SOFTWARE}

Models optimizing micropowers help evaluate designs of both off-grid and grid-connected power systems for several applications. When a power system is designed, many decisions must be taken into account about the system configuration: Which component should be included in the system design? How many components (and components' size) should be used? The large number of technology options and variation in technology costs, and the energy resources' availability make these decisions difficult. In order to develop a hybrid power system model that identify the economic configuration of PV and Wind with Diesel generation, the National Renewable Energy Laboratory (NREL) [14] has usesd Hybrid Optimization of Multiple Electric Renewable (HOMER) software, NREL's micropower optimization model. HOMER, due to its flexibility, is useful in evaluating design issues in the planning and early decision-making phase of rural electrification projects. It evaluates a range of equipment options over varying constraints and sensitivities to optimize small power systems. HOMER's optimization and sensitivity analysis algorithms make it easier to evaluate many possible system configurations. To use this software, the model is provided with inputs, which describe technology options, component costs, and resource availability. These inputs are used by HOMER to simulate system configurations (or combinations of components) and generate results that can be seen as a list of feasible configurations sorted by net present cost. It also displays simulation results, compares configurations and evaluates them on economic and technical basis. When we need to explore changes' effects in resource availability and economic conditions might have on the cost-effectiveness of different system configurations, it is possible to use the model to perform sensitivity analyses. Sensitivity analysis results can be used to identify the factors that have the greatest impact on the design and operation of a power system. HOMER Pro is used to design and find optimized configurations of a hybrid power system in terms of stability, low cost, size and number of components, prior to installation $[15,16]$. The aim of this paper is to design a hybrid power system model with metrological data inputs, also to describe feasible technology, component costs based on the availability of resources. Data considered as inputs are used to simulate different system configurations, or combinations of components, and generate results viewed as a list of feasible configurations sorted by net present cost [17]. Present work purposes simulation of an hybrid power system, economic combination PV, Diesel Generator, Converter and battery storage [18-19]. The simulated results using HOMER give the comparative economic analysis with each configuration and evaluate the best configuration. This is evident in the results presented in this paper. Thus, HOMER is advantageous in performing energy balance configuration for each hour to choose whether configuration is feasible or not. For the same feasible combination the total cost of operation is estimated over the life time of the project at a particular area before installation. [15, 20-23].

\subsection{Step 1: Presentation of the hybrid system installation site}

There is many favorable sites for producing the decentralized energy throughout the Algerian territory. Since the choice of a particular site is not $\mathrm{p}$ an easy task, our point of interest being was focused on a hybrid PV-Diesel production, although each system exhibits a number of advantages over the other. The HES sizing (dimensioning) obviously depends on the available energy resources as well as the constraints of their using, and the solar potential (SP) over a used year to realize the HES dimensioning is available in the database provided that our software provide [21-23].

\subsection{Step 2: Evaluation of the energy resource available on the site}

For SP data, only entering the longitude and latitude of the desired location is required, and just a click on the "Get Data Via Internet" icon provides results. Figure 2 shows the solar radiation data for the study area. It can be observed that the radiation varies between $2.310 \mathrm{kWh} / \mathrm{m}^{2} /$ day for the month of December and $7.16 \mathrm{kWh} / \mathrm{m}^{2} /$ day for the month of July with an annual average of $4.80942 \mathrm{kWh} / \mathrm{m}^{2} /$ day. It can also be noted that the highest radiation values are observed during the months of March to September while the smallest values are observed during the months of October to February. The monthly clarity index is defined as the ratio of ground radiation to extraterrestrial radiation. The values of the latter vary according to the places and the seasons. In Figure 2, it is observed that the monthly index of clarity varies between 0.522 in January (rainy season) and 0.634 in July (dry season), and the annual clarity index is equal to 0.581 . It can be observed that the radiation varies between $2.31 \mathrm{kWh} / \mathrm{m}^{2} /$ day for December and $7.16 \mathrm{kWh} / \mathrm{m}^{2} /$ day for July with an annual average of $4.80942 \mathrm{kWh} / \mathrm{m}^{2} /$ day. It can also be noted that the highest radiation values are observed during the period March to September while the smallest values are observed during the months of October to February. The monthly clarity index is defined as the ratio of ground radiation to extraterrestrial radiation. The values of the latter vary according to the places and the seasons. In Figure 2, it is observed that the monthly index of clarity varies between 0.522 in January (rainy season) and 0.634 in July (dry season), and the annual clarity index is equal to 0.581 [21-23]. 


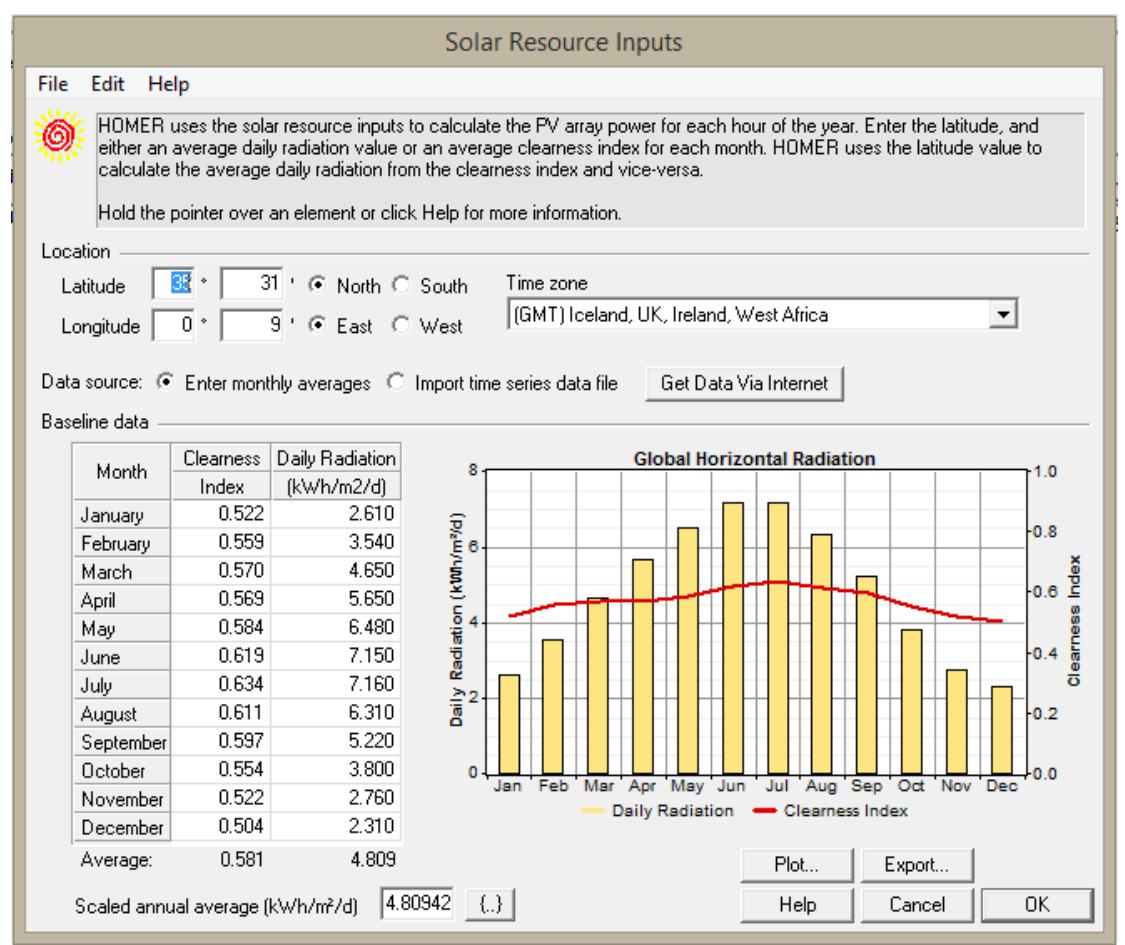

Figure 2. Solar radiation data for the study area

\subsection{Step 3: Evaluation of energy demand (load profile)}

In our case study, we imported a data-file from Mohammedia Sonelgaz database to present the load profile, as shown in Figure 3. Looking at Figure 4, it can be seen that this is a load with an average annual value of $123 \mathrm{kWh} / \mathrm{d}$ and an instantaneous power peak of $14.3 \mathrm{~kW}$ [21-23].

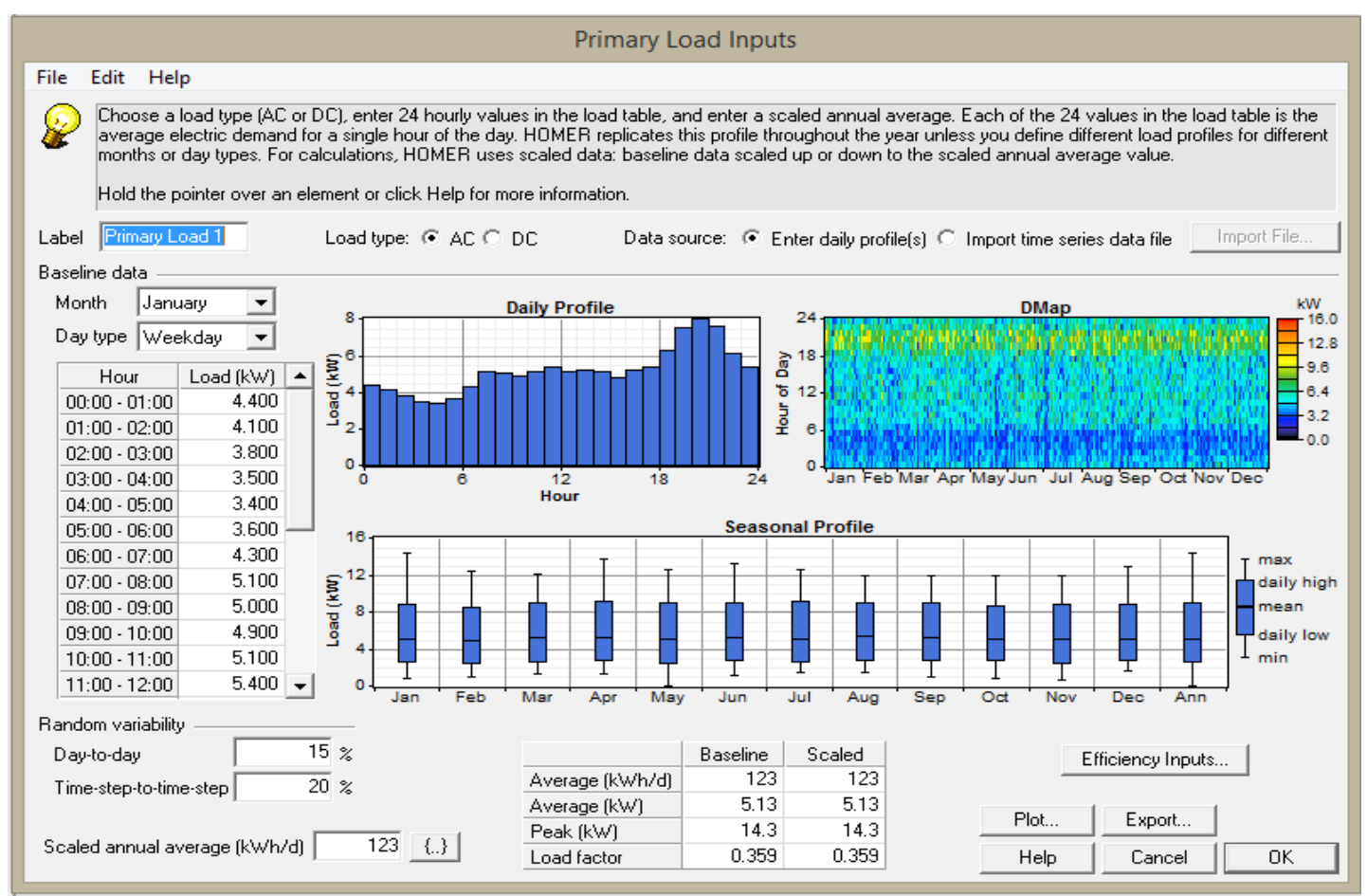

Figure 3. Load profile 


\subsection{Step 4: Starting calculations}

Once all data entered, we obtain the architecture of the system presented in Figure 4. Now it is enough to launch the calculation. A click on the button 'calculate' will display the results [21-23].

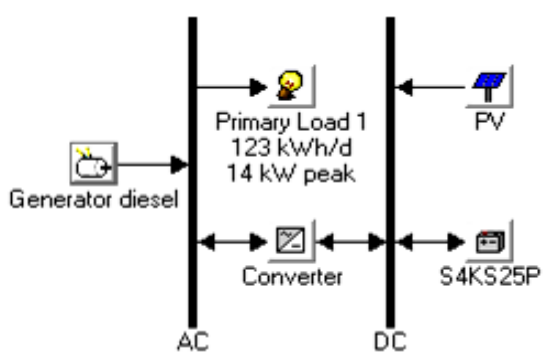

Figure 4. System architecture after entering the necessary data

\section{RESULTS AND DISCUSSIONS}

Considering all inputs, HOMER simulates repeatedly to get suitable solution. Optimization results are displayed in terms of categorized and overall, showing most feasible architecture which satisfied all inputs and constraints that designers give. After simulating all possible configurations, we obtained the overall results shown in Figure 5.

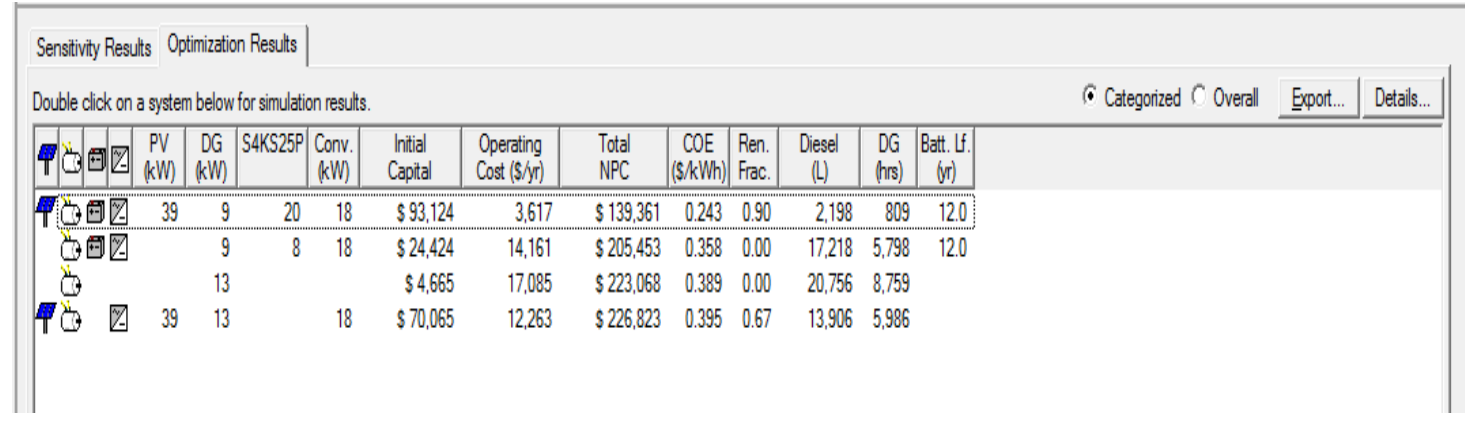

Figure 5. Result obtained after the first simulation

The results are ranked in order (from top to bottom) from the most profitable to the least profitable according to the NCP. It should be noted that the hybrid system is the least expensive configuration over the life of the project with $\$ 139,361$ and CEO of $\$ 0.243 / \mathrm{kWh}$. This system consists of a $39 \mathrm{~kW}$ PV field, a $9 \mathrm{~kW}$ diesel generator, a 20 -cell battery storage system and an $18 \mathrm{~kW}$ converter, with an investment cost of $\$ 93,124$ which is the highest compared to other configurations. In the simulation results window, several technical and economic details about each system configuration that HOMER simulates can be seen. Via a first double click is interested in the optimal configuration whose technical and economic details are presented thereafter.

\subsection{Production and consumption of electrical energy}

The production and consumption of electrical energy of the optimal configuration over a year in Figure 6. It should be noted that $90 \%$ of the site's needs will be provided by the PV generator, the remaining $10 \%$ being provided by the diesel generator energy source, which is equivalent to a total produced energy of $61278 \mathrm{kWh} /$ year $(100 \%)$. This energy distribution gives a renewable energy fraction of $90.5 \%$, which is satisfactory in view of the PV generator power $(39 \mathrm{~kW})$ and the storage capacity $(5 * 4)$ considered in the simulation. We also note that the fraction of $908 \%$ is an annual average, which is not constant over the whole year, it is linked to the variability of renewable resources. The sunniest months correspond to a high production by the PV with a low production by the GD and vice versa. 


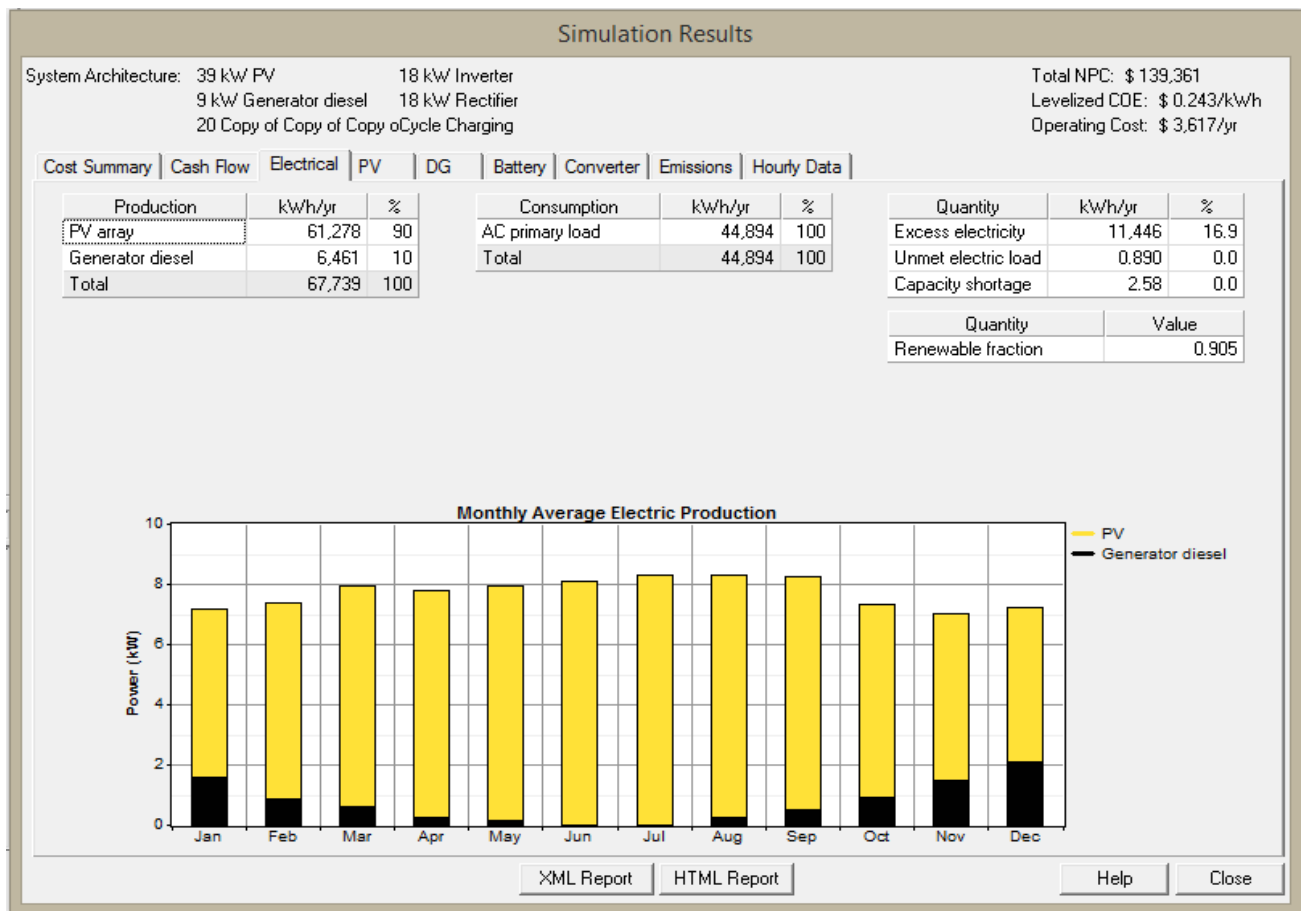

Figure 6. Production of monthly energy of the electrical energy of the optimal configuration

\subsection{Cost breakdown of the installation}

Figure 7 shows details of NPC by cost type (capital, replacement, maintenance and recovery operation) of the optimal configuration, where the distribution of each cost according to the components (PV, DG, battery and converter) is represented by different colors.

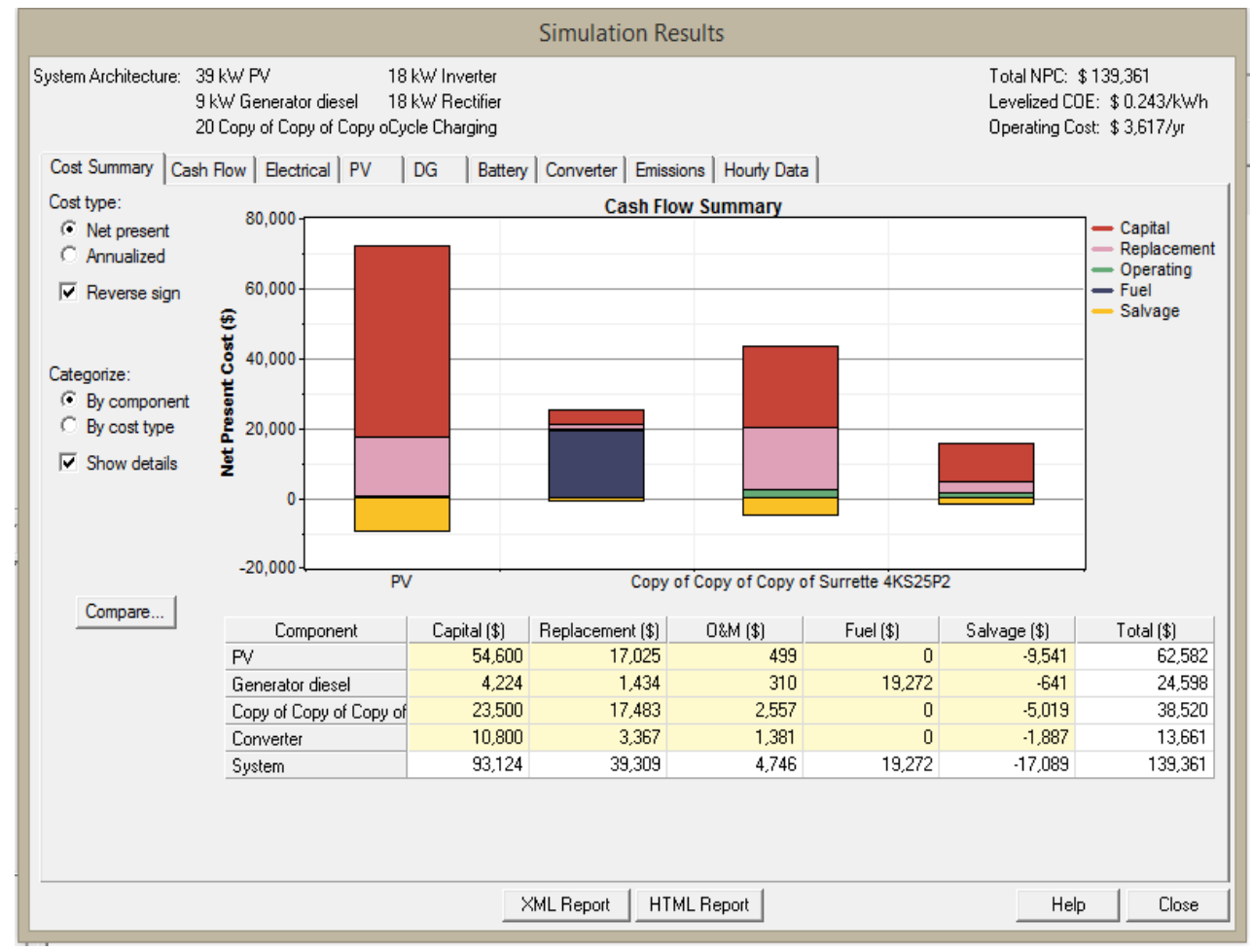

Figure 7. NPC Details by cost type 


\subsection{Comparison of SEH with diesel alone}

To show the reliability and profitability of the hybrid systems, it is interesting to make a comparison between this configuration and the other most used solutions such as the diesel alone, the PV alone as well as the network extension. If we look again at Figure 5, which shows the results obtained after the simulation, we see that the diesel solution alone is ranked last with a power of GD of $13 \mathrm{~kW}$, a NPC of $\$ 223068$ and a COE of $\$ 0.389 / \mathrm{kW}$. We double-click on this solution and extract all the technical, economic and environmental parameters. It is observed that all the hybrid system parameters are more advantageous compared to diesel alone, with the exception of the initial cost, which is minimal in the conventional solution. Much of the total cost of this latter solution comes from operating and maintenance costs that are mostly related to the use of fuel. The fuel consumption with increasing NPC and COE of this last solution. Looking at the technical performance of each solution, we noticed that production of electric energy is greater in the hybrid system than in the diesel system alone, this is essentially due to an excess of energy greater than the conventional solution. We can be concluded that, at the technical, economic and environmental levels, the hybrid system is more profitable than the conventional solution (diesel only). Figure 8 (a, b) and show the cost of the grid extension threshold compared to both hybrid and diesel systems alone. The hybrid system is profitable if the distance from the village to the transformer station is greater than $8.4 \mathrm{~km}$ but the diesel system alone is profitable if and only if the village is located at a distance of more than $16.6 \mathrm{~km}$.

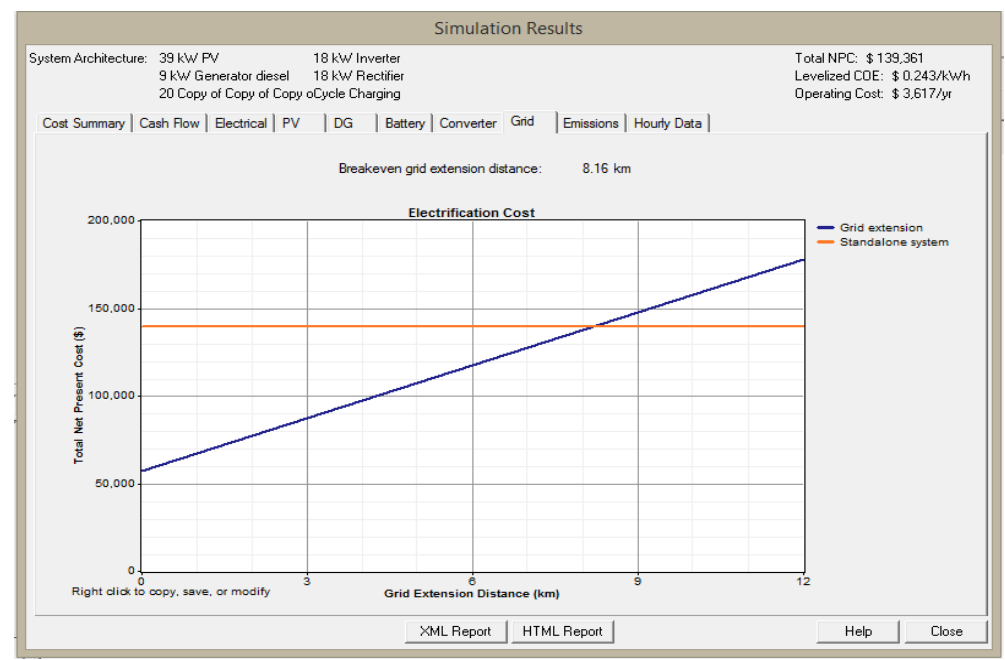

Figure 8. (a) Comparison between SEH and the network extension

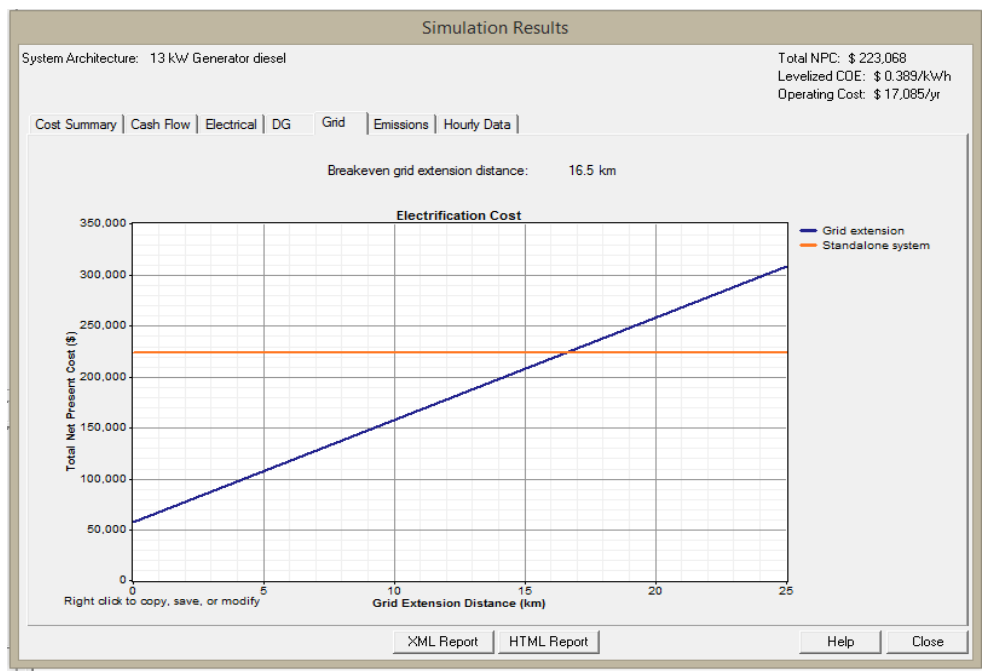

Figure 8 (b). Comparison between diesel alone and network extension

Figure 8. (a) Comparison between SEH and the network extension, (b) Comparison between diesel alone and network extension 


\subsection{Sensitivity analysis}

The most interesting option offered by HOMER is the sensitivity analysis. Once the systems are optimized, we can do this analysis. We must first identify the data deemed sensitive, less reliable or more random. This type of analysis makes it possible to verify the results obtained taking into account these particular data. In the first stage, the initial values of diesel $(0.625 \$ / \mathrm{L})$ and PV $(1400 \$ / \mathrm{kW})$ are set, and the other parameters (average solar radiation and the load) are varied. The graphical results shown in Figure 9 (a) are obtained.

The irradiation have not a great influence on the results, against a decrease and increase (between $47.91 \%$ and more) of solar radiation the hybrid system is the best solution. This hangs for other situations the DG / batteries is favorable. Here diesel without storage is adopted for small values of the load. Then we will set the price of diesel and we increase the price of PV more than $25 \%$ and varies the other parameters.

For a $25 \%$ increase in the PV price, we find that it is the same thing as the first case as shown in Figure 9 (b), except that here the diesel/battery between housing in the area that has been occupied by the hybrid system. In Figure 9 (c), one can observed that for an increase in PV prices of $70 \%$ the DGs/batteries dominate, however the $\mathrm{SEH}$ is favored for some value of the electric charge.

It can be seen from Figure 9 (d-f) a decrease of PV prices to a positive circumstance over the solution compared to other solutions, whereas for a decrease of more than the initial PV price, the hybrid zone or solution is Optimal becomes bigger and majority and leaves only a small space to the diesel battery solution for higher loads. The diesel solution alone does not appear. It can also be noted that for all PV prices considered in this analysis, irradiation has a negligible and sometimes zero influence on the results obtained.

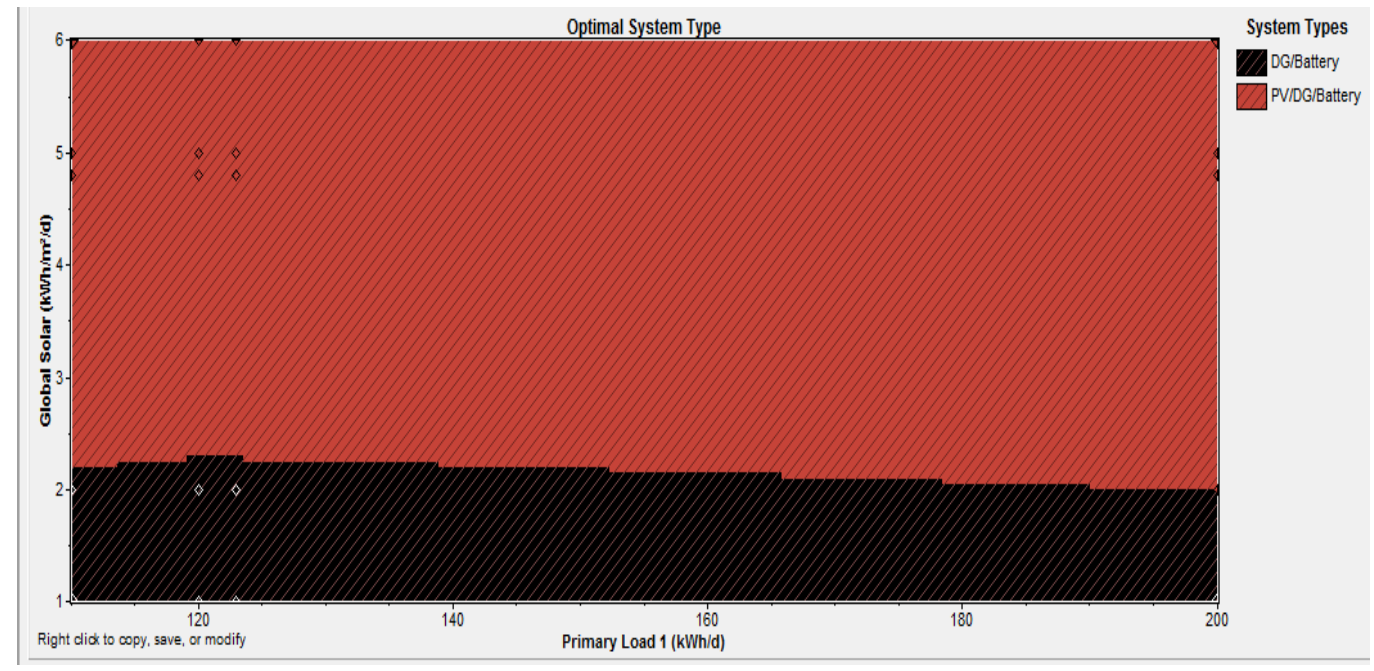

Figure 9 (a). Sensitivity study: Irradiation and charge variation, diesel price and fixed PV

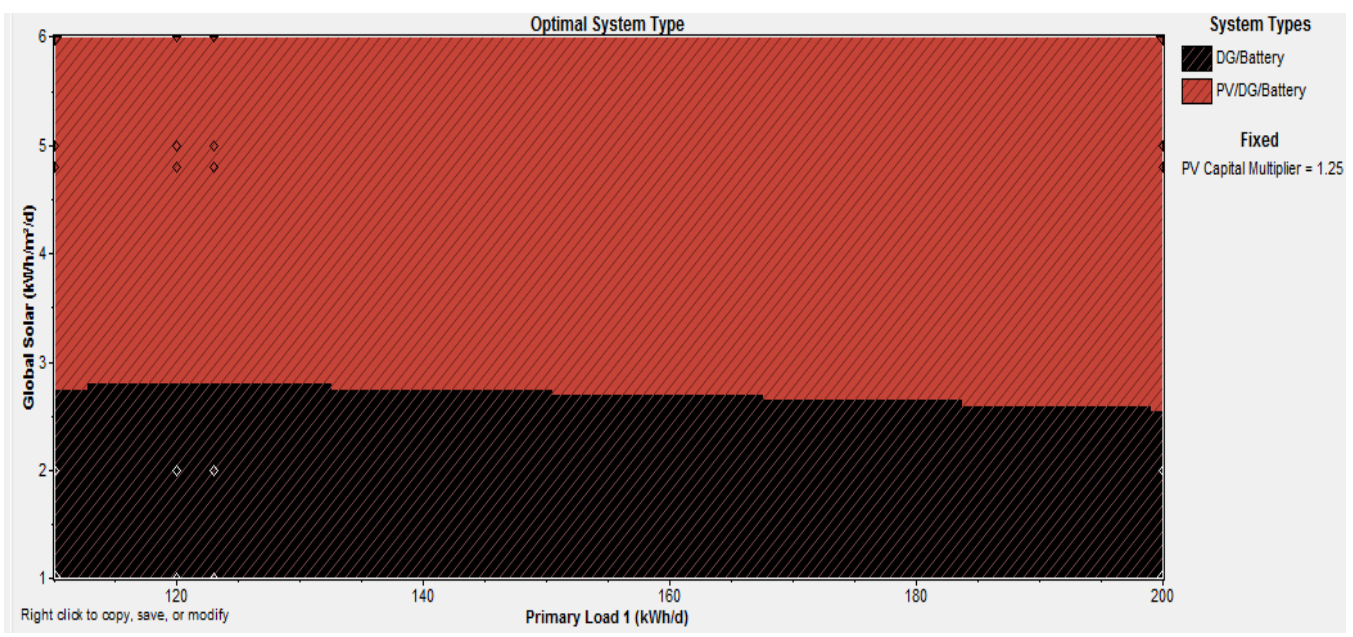

Figure 9 (b). Sensitivity study: Irradiation and load variation, fixed diesel price and PV increase $25 \%$ 


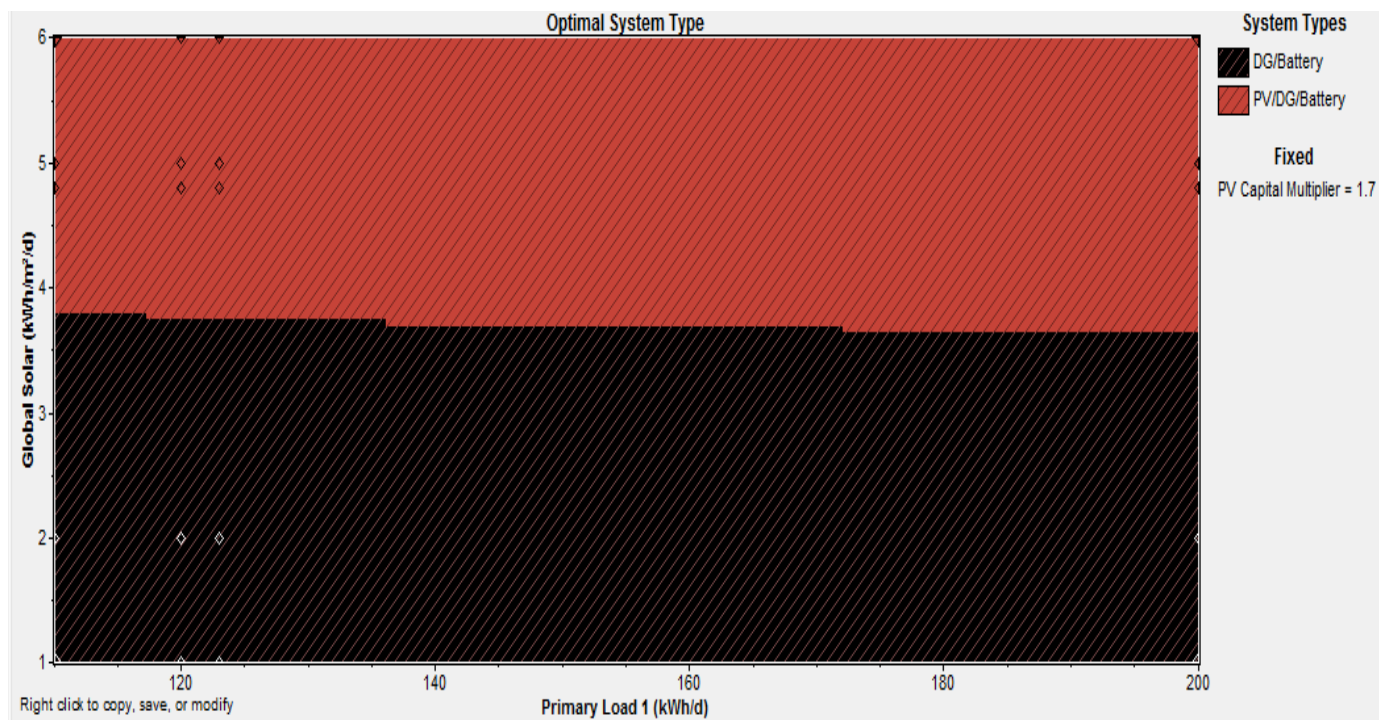

Figure 9 (c). Sensitivity study: Irradiation and load variation, fixed diesel price and PV increase $70 \%$

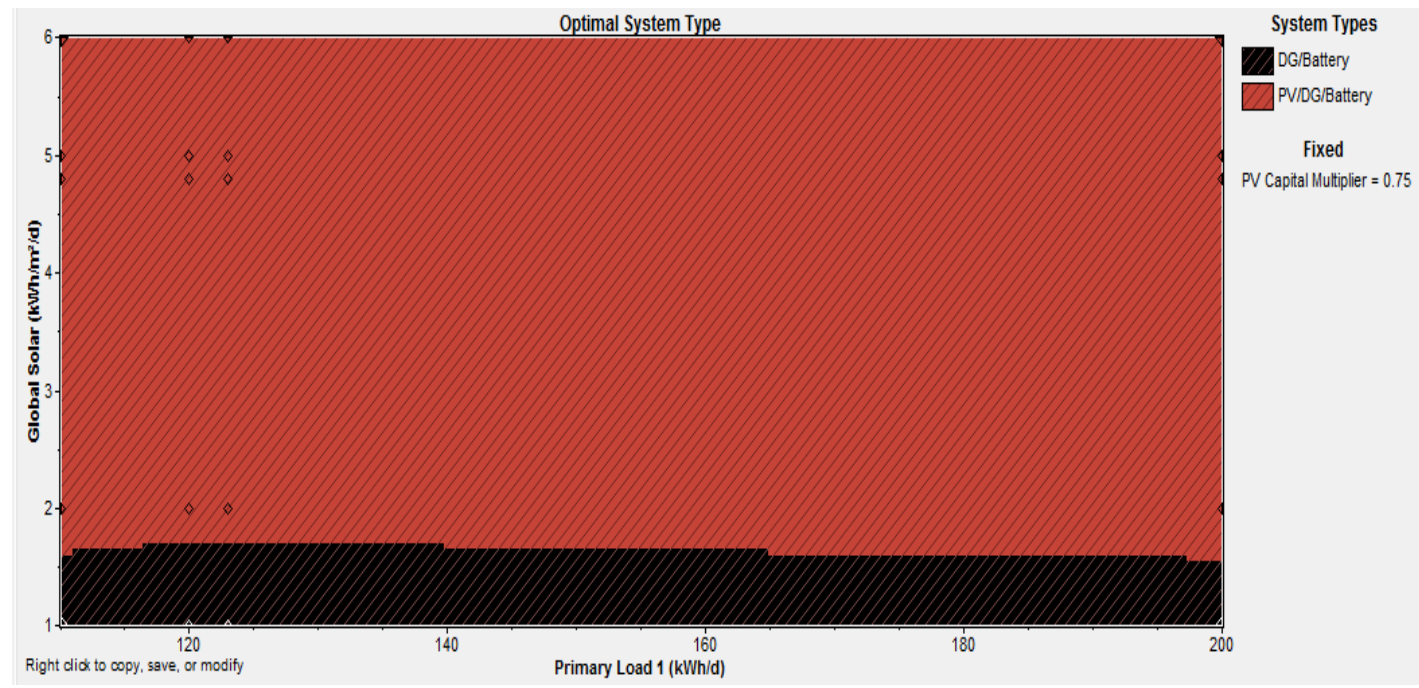

Figure 9 (d). Sensitivity study: Irradiation and load variation, fixed diesel price and PV decrease $25 \%$

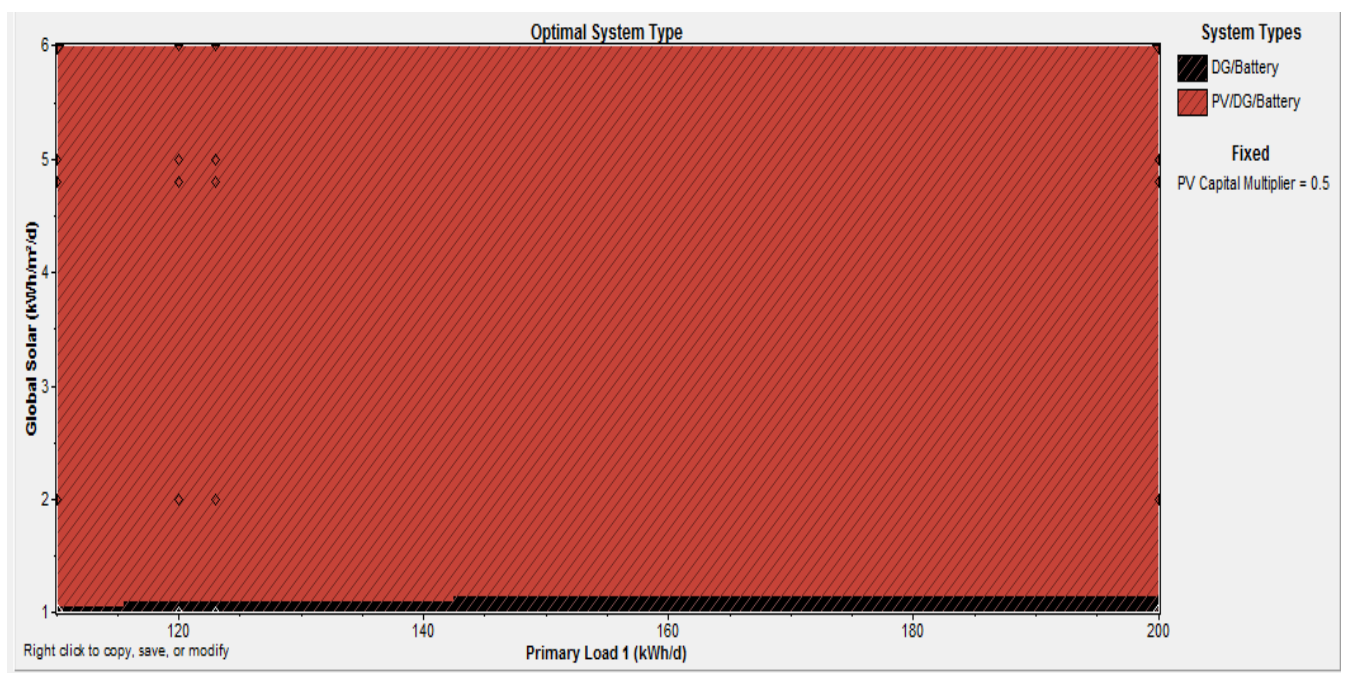

Figure 9 (e). Sensitivity study: Irradiation and load variation, fixed diesel price and PV decrease 50\% 


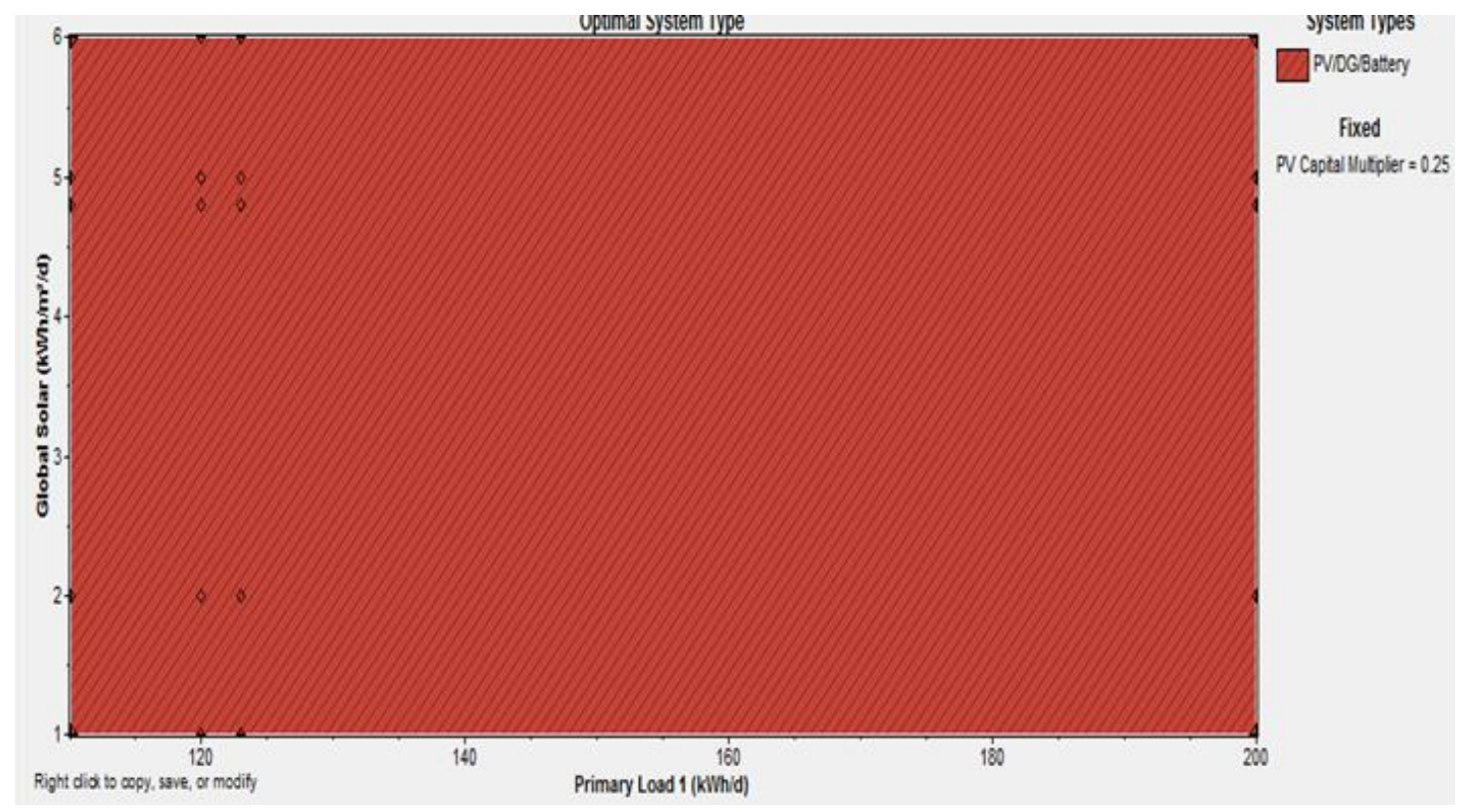

Figure 9 (f). Sensitivity study: Variation in irradiation and load, fixed diesel price and PV reduction $75 \%$

Figure 9. (a) Sensitivity study: Irradiation and charge variation, diesel price and fixed PV, (b) Sensitivity study: Irradiation and load variation, fixed diesel price and PV increase 25\%, (c) Sensitivity study: Irradiation and load variation, fixed diesel price and PV increase $70 \%$, (d) Sensitivity study: Irradiation and load variation, fixed diesel price and PV decrease $25 \%$, (e) Sensitivity study: Irradiation and load variation, fixed diesel price and PV decrease 50\%, (f) Sensitivity study: Variation in irradiation and load, fixed diesel price and PV reduction $75 \%$

\section{CONCLUSION}

This work presents an economical expediency of grid connected hybrid power system for rural area applications in a northern city of Algeria, Mascara, Ferraguig. The analysis is carried out by investigating mainly the potentials of solar energy and collecting data from different sources. We have focused in this work on technical, economic and environmental profitability of the hybrid system compared to other conventional solutions used to supply isolated sites in Algeria. HOMER software is used to analyze the available data and economic feasibility of the proposed hybrid power system. It has been adopted to optimize such system, combining two energy resources, one renewable created by PV, the other non renewable generated by a fuel generator. This system is recommended to a school in Ferraguig area located in the north of Algeria. The daily primary load considered is $4.8 \mathrm{kWh}$, with peak of nominal power as $1.5 \mathrm{~kW}$. Wind speed is very low in Ferraguig, so we don't purpose a wind energy resources. Also, wind turbines' price is very expensive and provides low energy production and less than solar sources production. Most costeffective PV/battery systems depend mostly on the reliability, solar resource, and diesel fuel price. Such systems become more cost-competitive with hybrid systems over a larger range of loads, by allowing some small percentage of the load to go unserved throughout the year. HOMER has confirmed here the intuitive notion that locating a system in a region of higher average solar radiation favors PV/battery systems relative to hybrid systems. Since fuel price had surprisingly little effect on the threshold between PV/battery and hybrid systems over the range of small systems considered here once high reliability is required, an optimal solution, using Homer, for the proposed hybrid system was expected, and a PV cost of is 57,35\% of the total hybrid system was achieved. This system produces $96 \%$ of all hybrid system production, but the generator provides just 4\%. For (Jun, July, Aug and Oct) months, PV production was 100\%, which explains the benefits of the proposed system. In addition, fuel cost is cheaper in Algeria. PV presents $28 \%$ with batteries storage and $64 \%$ without it. The system offer several benefits such as utilization rate of PV generation is high, load can be satisfied in the optimal way. To summarize, the results obtained show that the site chosen with the local resources and the characteristic of the load to be fed, the hybrid system is the optimal solution compared to the other solution namely the Diesel alone and the diesel with batteries. PV alone does not appear in the solution displayed by the software because we demanded a continuous supply of the uninterrupted load envisaged. At the same time, SEH has a lot of technical and economical advantage and 
even ecological in comparison with Diesel alone. The sensitivity analysis shows that lower PV prices and higher diesel costs in the future will favor the use of HEU. The Algerian climate is very suitable for the installation of this type of system for the decentralized production of electrical energy in order to supply remote sites of the electricity network. SEH has remarkable reliability for increased load in the future.

\section{NOMENCLATURE}

\begin{tabular}{|c|c|c|c|}
\hline & Nomenclature & Sonelgaz: & erian-National Corporation of Electricity \& Gas \\
\hline$G E$ & Generator & $T_{c}$ & Cell effective temperature \\
\hline$P V$ & Photovoltaic & $A$ & $\mathrm{PV}$ generator area $\left[\mathrm{m}^{2}\right]$ \\
\hline HOMER & $\begin{array}{l}\text { Hybrid Optimization of Multiple Electric } \\
\text { Renewables }\end{array}$ & $E_{g e n}$ & $\begin{array}{l}\text { Generator's total annual electrical production } \\
{[\mathrm{kWh} / \mathrm{yr}]}\end{array}$ \\
\hline$D C$ & Direct Current & $m_{\text {fuel }}$ & Generator's total annual fuel consumption $[\mathrm{kg} / \mathrm{yr}]$ \\
\hline$A C$ & Alternating current & $L H V_{\text {fuel }}$ & Lower heating value of the fuel $[\mathrm{MJ} / \mathrm{kg}]$ \\
\hline$C_{N P C}$ & Net present cost of system & $\eta_{g e n}$ & $\begin{array}{l}\text { Average electrical efficiency of the generator over } \\
\text { the year[\%] }\end{array}$ \\
\hline$C_{\text {ann,tot }}$ & Total annualized $[\$ / y r]$ & ngen,tot & $\begin{array}{l}\text { Average total efficiency of the generator over the } \\
\text { year[\%] }\end{array}$ \\
\hline$I$ & Annual interest rate $[\%]$ & $F$ & Fuel consumption this hour [L] \\
\hline$N$ & Number of years & FO & $\begin{array}{l}\text { Generator fuel curve intercept coefficient } \\
{[\mathrm{L} / \mathrm{hr} / \mathrm{kWrated}]}\end{array}$ \\
\hline$R_{\text {proj }}$ & Project life time [yr] & F1 & Generator fuel curve slope $[\mathrm{L} / \mathrm{hr} / \mathrm{kW}]$ \\
\hline$C R F(i, N)$ & Capital recovery factor & Ygen & Rated capacity of the Generator $[\mathrm{kW}]$ \\
\hline$C O E$ & Levelized cost of energy & Pgen & Output of the generator in this hour $[\mathrm{kW}]$ \\
\hline$E_{\text {prim }}$ & Total amount of primary load $[\mathrm{kWh} / \mathrm{yr}]$ & Crep,gen & Generator replacement cost \\
\hline$n_{r}$ & Reference module efficiency, & Rgen,h & Generator lifetime[hr] \\
\hline$T_{\text {cref }}$ & $\mathrm{R}$ cell temperature in degree Celsius & Ngen & $\begin{array}{l}\text { Number of hours the generator operates during one } \\
\text { year }[\mathrm{hr} / \mathrm{yr}]\end{array}$ \\
\hline$G(t)$ & Solar irradiation in tilted module plane $\left[\mathrm{Wh} / \mathrm{m}^{2}\right]$ & Ftot & $\begin{array}{l}\text { Total annual generator fuel consumption [L/yr, } \\
\mathrm{m} 3 / \mathrm{yr} \text {, or } \mathrm{kg} / \mathrm{yr}]\end{array}$ \\
\hline$B$ & Temperature coefficient & $T_{c}$ & Cell effective temperature \\
\hline
\end{tabular}

\section{REFERENCES}

[1] N. Balbheem and S. Patil Kulkarni, "Exploring the Performance Extents of Hybrid Renewable Energy Systems," International Journal of Advance Research, Ideas and Innovations in Technology, vol. 3, no. 2, pp. 1212-1222, 2017.

[2] Mehreen Gul, Mehreen Gul, Yash Kotak, Tariq Muneer, "Review on recent trend of solar photovoltaic technology, Exploration \& Exploitation," vol. 34, no. 4, pp. 485-526, 2016.

[3] Peter J. Schubert, "Renewable Energy for Human Sustainability (Oxford Research Encyclopedia of Environmental Science) Subject: Sustainability and Solutions, Online Publication, Apr 2016, pp 1-33.

[4] P. Docampo, S. Guldin, T. Leijtens, N. K. Noel, U. Steiner, and H. J. Snaith, "Lessons Learned: From DyeSensitized Solar Cells to All-Solid-State Hybrid Devices," Adv. Mater. 2014, Wiley-VCH Verlag GmbH \& Co. KGaA, Weinheim, pp 1-18.

[5] A.N Supriyadiet T. Hashiguchi, "Control Scheme of Hybrid Wind-Diesel Power Generation System," From turbine for wind farms, JaponIndonisia, April 2011.

[6] R. Sebastiin, M. Castro, E. Sancristobal, F. Yeves and J. Peire, "Approaching hybrid wind-diesel systems and Controller Area Network," IECON 02, IEEE Conference, pp- 2300-2305, Nov 2002

[7] D. Rekioua, Z. Roumila et T. Rekioua, "Etude d'une centrale hybride photovoltaïque - éolien - diesel," Université A. Mira, Bejaia. Bejaia, Algérie 2008.

[8] Nahid-Al-Masood, RifatMirza, Jubaer Ahmed, "Design of a Cost Effective Off-Grid Wind-Diesel Hybrid Power System in an Island of Bangladesh," World Academy of Science, Engineering and Technology, 201.

[9] P.A. Stott and M.A. Mueller, "Modelling fully variable speed hybrid wind diesel systems," UPEC'06, vol 1, pp212-216, Newcastle USA, Sep 2006.

[10] New world encyclopedia, "Algeria," http://www.newworldencyclopedia.org/entry/Algeria

[11] Britannica, "Solar Panel Technology", https://www.britannica.com/technology/solar-panel

[12] Climate-data, "Climate Mascara" https://en.climate-data.org/africa/algeria/mascara/mascara-6186

[13] http://eoseb/arc.nasa.gov/cgi-bin/sse/grid.cgi , and http://rredc.nrel.gov/solar).

[14] Antonio Jimenez, "Chefornak Energy Configuration Options Energy Infrastructure Optimization to Reduce Fuel Cost and Dependence in Chefornak, " https://www.nrel.gov, Alaska August 2018

[15] M. A. Matinn, A. Deb, A. Nasir, "Optimum Planning of Hybrid Energy System using HOMER for Rural Electrification," International Journal of Computer Applications (0975 - 8887), vol. 66, no. 13, March 2013.

[16] S. S. Murthy, S. Mishra, G. Mallesham and P. C. Sekhar, "Voltage and Frequency control of wind diesel hybrid system with variable speed wind turbine," IEEE magazine 20-23 December 2010.

[17] P. S. Panickar, S. Rahman, S. M. Islam and T. L. Pryor, "Adaptive control strategies in wind-diesel hybrid systems," Curtin University, Western Australia. 
[18] N. Vania and V. Kharea, "Rural Electrification System based on Hybrid Energy System Model Optimization using HOMER," CJBAS, vol. 01, no. 01, pp. 19-25, August 2013.

[19] R. Huang, S. H. Low, U. Topcuand K. Mani Chandy, "Optimal Design of Hybrid Energy System with PV/ Wind Turbine/ Storage: A Case Study," Virtual Power Plants, Distributed Generation, Microgrids, Renewable and Storage International IEEE conference, 17-20 Oct. 2011.

[20] M. Nurunnabi and N. K. Roy, "Grid connected hybrid power system design using HOMER," 2015 International Conference on Advances, Dhaka, 2015, pp. 18-21.

[21] Jyoti B. Fulzele, Manoj B. Daigawane \& Prema M. Daigawane, "Design of hybrid PV-wind stand-alone renewable energy system: Case study," Journal of Information and Optimization Sciences, vol. 39, no. 1, pp. 345-355, 2018.

[22] M. S. Ismail, M. Moghavvemi, T.M.I. Mahlia, "Design of an optimized photovoltaic and microturbine hybrid power system for a remote small community: Case study of Palestine," Energy conversion and management, vol. 75, pp. 271-281, 2013.

[23] N. A. bte Abdull Razak, M. M. bin Othman and I. Musirin, "Optimal sizing and operational strategy of hybrid renewable energy system using homer," 2010 4th International Power Engineering and Optimization Conference (PEOCO), Shah Alam, 2010, pp. 495-501. 